\title{
Negative Pressure Wound Therapy (NPWT) in Groin Wounds After Lymphadenectomy in Vulvar Cancer Patients
}

\author{
KATRIN CHRISTINE ASCIUTTO ${ }^{1}$, STEFAN ACOSTA ${ }^{2,3}$ and CHRISTER BORGFELDT ${ }^{1}$ \\ ${ }^{1}$ Department of Obstetrics and Gynecology, Skåne University Hospital, Lund Unviversity, Lund, Sweden; \\ ${ }^{2}$ Department of Clinical Sciences, Lund University, Malmö, Sweden; \\ ${ }^{3}$ Vascular Center, Skåne University Hospital, Malmö, Sweden
}

\begin{abstract}
Background/Aim: Vulva cancer surgery is associated with a high level of morbidity mostly due to wound healing disorders in the inguinal region following lymphadenectomy. Our aim is to evaluate the feasibility of negative pressure wound therapy (NPWT) using the PICO ${ }^{T M}$ device in groin wounds after lymphadenectomy. Patients and Methods: The groins of twenty patients who underwent bilateral lymph node dissection were dressed with the PICO ${ }^{T M}$ device. All patients were followed prospectively with clinical controls up to three months postoperatively using a standardized study protocol. Results: A total of 11 patients (55\%) developed a surgical site complication (SSC). One patient suffered from a wound rupture two days after surgery, six a lymphocele and four a surgical site infection. Operation time, blood loss, number of lymph nodes removed, length of hospital-stay and duration of PICO ${ }^{T M}$ treatment did not differ between women with and without SSCs. Conclusion: NPWT using the PICO ${ }^{T M}$ device seems to be a feasible method to reduce the severity of healing disorders in the groin after lymphadenectomy in vulva cancer patients.
\end{abstract}

Vulva cancer accounts for $1 \%$ of all malignancies in women, and for about $5 \%$ of all the gynecological cancers. It usually occurs in postmenopausal women but its incidence is raising in younger women $(1,2)$. The majority of vulva cancer patients have lesions limited to the vulva that are according to the International Federation of Gynaecology and Obstetrics (FIGO) classification, defined as stage I or II disease in case of negative lymph nodes in the groin or as

This article is freely accessible online.

Correspondence to: Katrin Christine Asciutto, Department of Obstetrics and Gynecology, Skåne University Hospital, Klinikgatan 12, SE-221 85 Lund, Sweden. Tel: +46 46171000, Fax: +46 46157868, e-mail: christine.asciutto@yahoo.com

Key Words: NPWT, lymphadenectomy groin, vulvar cancer. stage III disease if lymph node metastasis is present (3). Most women suffering from early stage squamous vulva cancer can be treated with surgery consisting of either vulvectomy or wide local excision, combined with a uni-or bilateral radical lymphadenectomy or sentinel node extirpation in the groin. Even though the sentinel node concept shows excellent results in terms of overall survival, low complication and recurrence rates, it is only indicated for patients with small uni-focal cancer lesions and clinical negative lymph nodes $(4,5)$. Approximately $50 \%$ of all vulva cancer patients need a radical inguino-femoral lymphadenectomy due to large tumor size, multifocal disease or the presence of confirmed lymph node metastasis and/or suspicious bulky nodes in the groin $(3,6,7)$.

According to retrospective studies $(8,9)$ a radical staging procedure in the groin is associated with a high level of morbidity due to postoperative wound healing complications. About $30 \%$ of patients suffer from chronic lymphatic drainage problems, and the risk of developing a surgical site infection (SSIs) or a wound rupture is estimated to about 30$40 \%$ (10-13). Furthermore, healing disorders in the groin might jeopardize the initiation of adjuvant radiation or combined chemoradiation therapy in patients with metastasis or insufficient resection margins.

In order to find new strategies for the prevention and treatment of wound healing complications, we investigated prophylactic NPWT in early stage vulva cancer patients. For this purpose we used a single-use, canister-free NPWT device, which operates at a preset level of-80mm $\mathrm{Hg}$ and works predominantly by evaporative loss (14). While the majority of the lymphatic wound fluid is still removed by active suction drains, the NPWT dressing is meant to act as a complementary agent, facilitating the wound healing process by i) accelerating internal lymph drainage, ii) evaporating additional wound exudate, and iii) reducing the lateral tension on the closed wound edges (14-16).

As there are no published data regarding the clinical efficacy of NPWT on surgically closed incisions following lymphadenectomy in the groin, we decided to prospectively 
evaluate the feasibility of prophylactic NPWT in 20 vulvar cancer patients, prior to the initiation of a prospective randomized controlled trial.

\section{Patients and Methods}

In the presented case series, all included patients were followed prospectively after undergoing surgery for vulva cancer over a period of at least three months.

All patients with early stage vulva cancer who were scheduled for vulvectomy and bilateral lymph node dissection in the groin at the gynecological department at the university hospital in Lund between January 2017 and January 2018 were asked to participate in the present pilot study. Each participant was assigned a standardized study protocol following written informed consent. Exclusion criteria were i) an incapability of the patient to understand the study and ii) any condition related to linguistic or cognitive issues.

Study procedures were reviewed and approved by the Regional Ethics Board in Lund (Reference number DNR 2017/10).

Surgical technique. In patients scheduled for complete lymph node dissection access to the groin was gained via an eight- to tencentimeter long skin incision, which was placed one-to-two centimeters below the inguinal ligament. The dissection of the nodecontaining fat pad was performed using bipolar scissors (Erbe, Tübingen, Germany) as electrosurgical device. The tissue was reflected medially of the femoral vessels and the saphenous vein. The specimen containing the superficial and deep inguinal nodes was removed in one piece. The saphenous vein could be preserved in all affected groins and detectable lymph vessels were sealed using electrosurgical cauterization. After placement of the active suction drains (see below) the wound was closed via adaption of the subcutaneous tissue using 3-0 absorbable suture (Vicryl, Ethicon, Solna, Sweden) and the skin (staples).

In women planned for sentinel node extirpation, $99 \mathrm{mTc}$ radiocolloid (Ultratechnekow FM, St. Louis, MO, USA) was injected intradermally around the vulva lesion one day before operation. Intraoperatively, sentinel node detection was performed with a hand-held gamma detection device. Once the sentinel nodes were identified, they were extirpated via a minor skin incision. No external drains were placed in women undergoing the sentinel procedure. Wound closure was performed in the same manner as described for patients undergoing complete lymphadenectomy.

All women received prophylactic administration of oral antibiotics consisting of a combination of metronidazol and sulfamethoxazole/trimethoprim or doxycycline in the morning at the day of the operation.

For the prevention of thromboembolic events patients were treated with a low weight molecular heparin (Innohep 4500 I.E., LEO Pharma, Ballerup, Danmark) for at least seven days after the operation.

Wound care. The first $\mathrm{PICO}^{\mathrm{TM}}$ dressings were applied on the groin wounds in the operation room under sterile conditions. All groin incisions were closed with staples and suction drains were placed in the wound beds, according to our study protocol. NPWT was applied with a single-use, canister-free instrument, the PICO $^{\text {TM }}$ device (Smith \& Nephew AB, Mölndal, Sweden). This device operates at a preset level of $-80 \mathrm{mmHg}$ and is equipped with a small portable battery-operated vacuum unit. The $\mathrm{PICO}^{\mathrm{TM}}$ device consists of a four-layer absorbent dressing, which has a total fluid management capacity of up to $200 \mathrm{ml}\left(20^{\prime} 15 \mathrm{~cm}\right.$ dressing pad) and works predominantly by evaporative loss (14).

In order to facilitate a tension-free application of the $\mathrm{PICO}^{\mathrm{TM}}$ device, we chose to locate the exit hole of the suction drain approximately $10 \mathrm{~cm}$ away from the lateral edge of the groin incision. When deciding on the size of the $\mathrm{PICO}^{\mathrm{TM}}$ dressing, we tried to cover the incision and the adjacent area in order to reduce the amount of interstitial fluid in the uncompromised surrounding tissue $(17,18)$ (Figure 1). We used a volume-controlled active drain management and indication for removal was given when drain production was less than $50 \mathrm{ml}$ within $24 \mathrm{~h}$. Independently of the output, suction drains were left in place for at least three days. In case of clinical infection signs, a wound culture was obtained in order to verify the presence of a pathogen microbial agent. An additional ultrasound examination of the groin area was performed if clinical signs of deep infection and/or impaired lymphatic drainage were present.

Follow-up. All included patients were followed-up for three months postoperatively. All patients received their first postoperative control before discharge. The first four follow-up examinations after discharge were scheduled at seven-day intervals in order to perform the clinical assessment and the change of the $\mathrm{PICO}^{\mathrm{TM}}$ dressing simultaneously.

PICO treatment was discontinued after the removal of all suction drains in the presence of satisfying healing conditions in the groin area. All patients received at least one postoperative change of the PICO dressing. If there were clinical signs of an upcoming severe healing disorder, such as wound rupture, the NPWT was interrupted earlier.

After removal of the PICO $^{\mathrm{TM}}$ dressings, the follow-up intervals were extended to 10 to 14 days. Healing disorders in the groin that became apparent within the first four weeks after the operation were classified as short-term complications and those who developed after four weeks as long-term complications. Pre- and postoperative surveillance data were assessed with the help of a standardized follow-up protocol containing information on i) SSC, ii) SSI, iii) operation related data, iv) patient characteristics and v) laboratory chemical results.

Regarding the latter, the highest postoperative values of Creactive protein (CRP) and white blood cell count (WBCC) were used for statistical analysis. Other patient related data, including i) histological findings, ii) cancer stage, iii) wound culture results and iv) type of antibiotic treatment were obtained from patients' files and added to the study protocol.

Independent of the need for adjuvant radiation or combined chemo-radiation therapy, all patients were scheduled for a further clinical control three months postoperatively. If necessary, those follow-up data were completed via phone interview or with the help of patient oncological charts.

Definitions. A wound healing complication was classified as a SSI if typical clinical infection signs and a positive wound culture were present. In order to improve the objectivity and standardization of the clinical observation, we also used both the Center for Disease Control and Prevention (CDC) classification and the ASEPSIS scoring system as additional assessment tools.

According to the CDC classification system, SSIs were classified as either superficial incisional, deep incisional or organ related (19). 


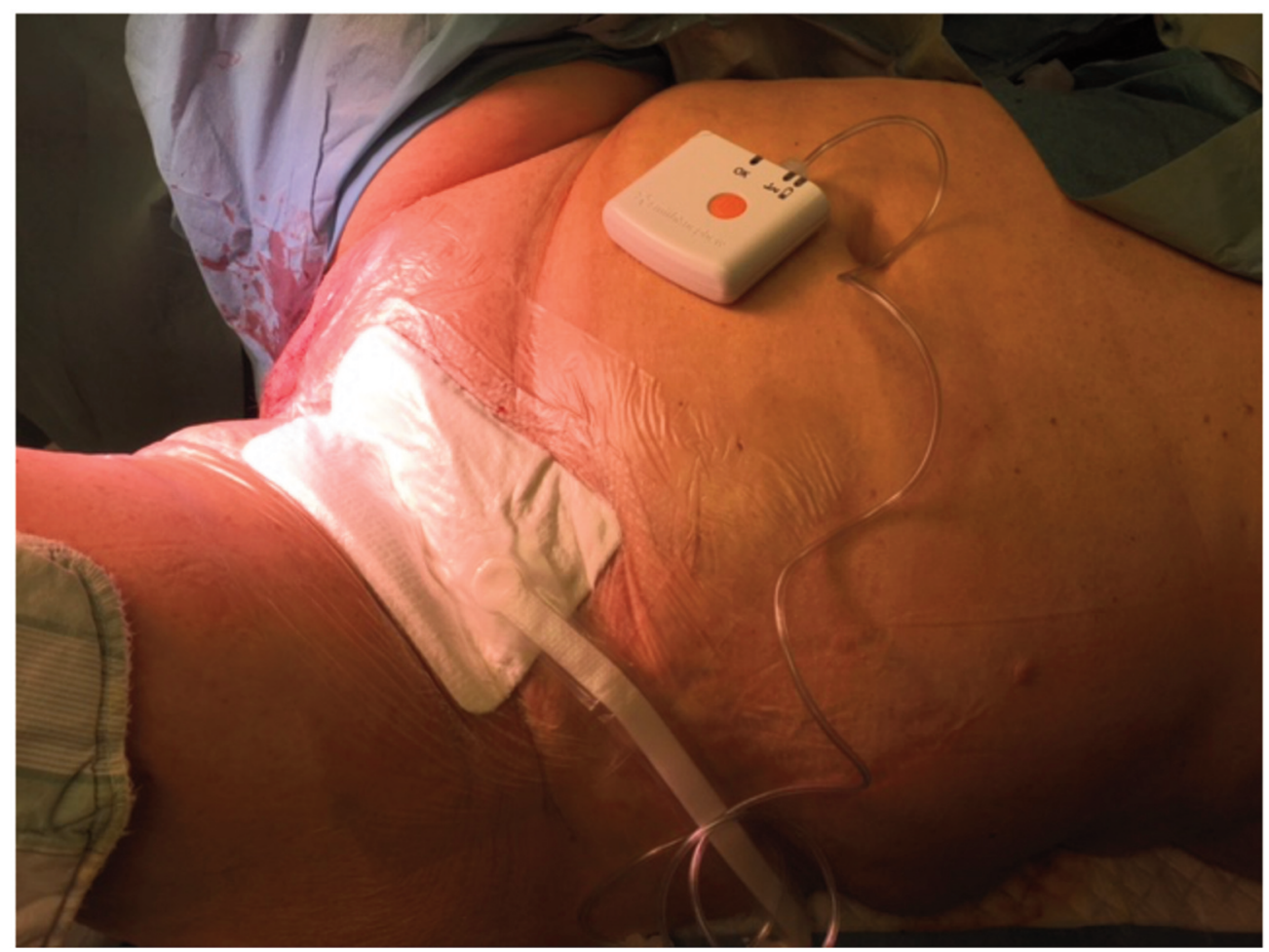

Figure 1. Tension-free application of the PICO ${ }^{T M}$ device covering the groin incision and the surrounding area in a sentinel patient.

The ASEPSIS classification was implied as a further objective categorization method to measure the severity of the documented SSI (20). This scoring system differentiates between: i) wound healing disorders (0-20 points), ii) minor wound infections (20-31 points), iii) moderate wound infections (31-40 points), and iv) severe wound infections ( $>40$ points). This numerical score represents the sum of several factors, including i) the administration of antibiotics, ii) the drainage of pus under local anesthesia, iii) the debridement of the wound under general anesthesia, iv) the presence of serous discharge, v) erythema, vi) purulent exudate and/or vii) the separation of deep tissue. In case of wound rupture, open vacuum-assisted wound closure (KCI Medical AB, Solna, Sweden) was used for treatment followed by operative wound revision.

The primary endpoint was the occurrence of SSC and especially of SSI during follow-up. Secondary endpoints included i) the measurement of re-admissions and re-operations due to SSCs, ii) the length of hospital stay and iii) the duration of $\mathrm{PICO}^{\mathrm{TM}}$ treatment.

Statistical analysis. All statistical comparisons were two-sided and $p$-Values less than 0.05 were considered statistically significant. Statistical analysis was performed using SPSS (PASW) version 22.0.0 (SPSS Inc., Chicago, IL, USA). The independent $t$ - test was used to compare the means between two unrelated groups. In case the dependent variable was continuous but not normally distributed, the Mann-Whitney $U$-test was used to compare the differences in medians between the two groups.

The observed frequencies of categorical variables were compared using the $c h i$-squared test. In cases of a small sample size the Fisher Exact Test was used for statistical comparison.

\section{Results}

Surgical management. Thirteen women underwent a complete, radical lymphadenectomy. The mean number of retrieved lymph nodes did not differ between the right (6.0) and the left groin (6.1). Seven women had a sentinel procedure with a mean number of 4 nodes harvested from the right and three from the left side $(p=0.43)$. Radical lymphadenectomy was performed in a total of 26 groins and the sentinel procedure in a total of 14 groins. None of the patients in the sentinel group were in need of further lymph node dissection as no metastatic cells were found on histopathological evaluation.

Except for one woman who was operated with the sentinel technique all patients received bilateral active suction drains, which were in place for at least three days. The mean time of drain treatment was 12 days on the right and 14 days on the left side $(p=0.44)$. The mean time of hospital stay was nine days ( $\mathrm{SD}+/-4.0$ days).

Wound outcomes. In 20 patients the $\mathrm{PICO}^{\mathrm{TM}}$ dressing was applied to the groin wounds on both sides. The mean time of treatment was 15.7 days (SD +/- 4.9 days). Patients who suffered from SSCs did not differ from patients without SSCs in terms of i) age $(p=0.061)$, ii) BMI $(p=0.57)$, iiii $)$ 
Table I. Patient overview of surgical site complications (SSC) and their classification.

\begin{tabular}{|c|c|c|c|c|c|}
\hline Type of SSC & $\mathrm{AB}$ treatment & Wound culture findings & CDC classification & ASEPSIS score & Comment \\
\hline $\begin{array}{l}\text { Wound rupture } \\
\text { perioperative }\end{array}$ & $\begin{array}{l}\text { Clindamycin } 900 \mathrm{mg} \times 3 \\
\text { for } 21 \text { days }\end{array}$ & $\begin{array}{l}\text { Streptococcus dysgalacticae } \\
\text { (group C) }\end{array}$ & Deep & $>40$ & $\begin{array}{l}\text { Severe wound } \\
\text { infection }\end{array}$ \\
\hline $\begin{array}{l}\text { Wound rupture+ } \\
\text { SSI }\end{array}$ & $\begin{array}{l}\text { Metronidazol } 1 \mathrm{~g}+\text { Heracillin } \\
1 \mathrm{~g} \times 3 \text { for } 21 \text { days }\end{array}$ & Anaerob bacteria+gram neg & Deep & $>40$ & $\begin{array}{l}\text { Severe wound } \\
\text { infection }\end{array}$ \\
\hline SSI & $\begin{array}{c}\text { Ciproloxacin } 1 \mathrm{~g}+\text { Metronidazol } \\
1 \mathrm{~g} \times 2 \text { for } 14 \text { days }\end{array}$ & $\begin{array}{l}\text { Anaerob bacteria } \\
\text { (Gram neg) }\end{array}$ & Superficial & 31 & $\begin{array}{l}\text { Moderate wound } \\
\text { infection }\end{array}$ \\
\hline SSI & $\begin{array}{l}\text { Amoxicillin } 1.5 \mathrm{~g} \times 2 \\
\text { for } 10 \text { days }\end{array}$ & $\begin{array}{l}\text { Streptococcus agalacticae } \\
\text { (group B) }\end{array}$ & Superficial & 29 & $\begin{array}{l}\text { Minor wound } \\
\text { infection }\end{array}$ \\
\hline SSI & $\begin{array}{l}\text { Dalacin } 600 \mathrm{mg} \times 3 \\
\text { for } 7 \text { days }\end{array}$ & $\begin{array}{l}\text { Anaerob bacteria } \\
\text { (Gram neg) }\end{array}$ & Superficial & 28 & $\begin{array}{l}\text { Minor wound } \\
\text { infection }\end{array}$ \\
\hline Lymphocyst & $\begin{array}{l}\text { Cefotaxim } 3 \mathrm{~g} \times 3 \\
\quad \text { for } 4 \text { days }\end{array}$ & Staphylococcus aureus & Superficial & 26 & $\begin{array}{l}\text { Minor wound } \\
\text { infection }\end{array}$ \\
\hline Lymphocyst & $\begin{array}{l}\text { Cefadroxil } 1 \mathrm{~g} \times 3 \\
\text { for } 14 \text { days }\end{array}$ & Negative & Superficial & 18 & $\begin{array}{l}\text { Disturbance of } \\
\text { healing }\end{array}$ \\
\hline Lymphocyst & $\begin{array}{l}\text { Cefadroxil } 2 \mathrm{~g} \times 2 \\
\text { for } 10 \text { days }\end{array}$ & $\begin{array}{l}\text { Anaerob bacteria } \\
\quad(\text { Gram neg) }\end{array}$ & Superficial & 20 & $\begin{array}{l}\text { Disturbance of } \\
\text { healing }\end{array}$ \\
\hline Lymphocyst & None & Not obtained & Superficial & 15 & $\begin{array}{l}\text { Disturbance of } \\
\text { healing }\end{array}$ \\
\hline Lymphocyst & None & Not obtained & Superficial & 20 & $\begin{array}{l}\text { Disturbance of } \\
\text { healing }\end{array}$ \\
\hline Lymphocyst & None & N.A. & Superficial & 15 & $\begin{array}{l}\text { Disturbance of } \\
\text { healing }\end{array}$ \\
\hline
\end{tabular}

SSI: Surgical site infection; SSC: surgical site complication, CDC: Centers for Disease Control and Prevention; CDC classification of surgical site infections (SSIs): superficial incisional, deep incisional, organ/space; N.A.: not available.

hypertension $(p=0.50)$, iv $)$ atrial fibrillation $(p=0.50)$, v) diabetes $(p=0.24)$ or vi) smoking $(p=0.50)$.

A total of 11 patients (55\%) developed an SSC during our follow-up period and a total of 13 groins were affected. Most healing disorders became apparent during the first two weeks after the operation $(\mathrm{n}=10 ; 50 \%)$. Readmission became necessary in three patients. While one woman was in need of operative revision due to a unilateral wound rupture, the other two patients were readmitted for clinical observation and prophylactic administration of oral antibiotics.

Surgical site complications. The occurrence of a lymphocele formation was the most common complication during the early postoperative period diagnosed in a total of six patients $(30 \%$, see Table I). At the time of diagnosis, ultrasound examination revealed that the accumulation of lymphatic fluid was about $2 \mathrm{~cm}$ in diameter in all affected groins $(\mathrm{n}=7)$. After continued $\mathrm{PICO}^{\mathrm{TM}}$ treatment for another 7 to 10 days with the suction drains in place there were no longer signs of impaired lymphatic drainage neither on clinical examination nor on ultrasound control.

SSIs were observed in four women, including three cases of an isolated, unilateral infection and one case of local infection adjacent to a unilateral wound rupture. In all four patients the SSI was characterized as superficial (Table I) as only a mild redness of the skin could be observed. A bacterial colonization could be identified in all affected groins and patients received oral antibiotics adapted to the sensitivity profile of the corresponding pathogen microorganism (Table I). In all four women, the infection resolved after a mean antibiotic treatment time of 11.2 ( $\mathrm{SD}+/-5.4$ days) days.

One patient developed a wound rupture two days after surgery. The other wound rupture occurred 14 days after completed $\mathrm{PICO}^{\mathrm{TM}}$ treatment and secondary to a spontaneous hemorrhage probably caused by therapy with a Factor Xa inhibitor.

Comparison of patient characteristics and surgical outcome between patients with and without SSCs. Patients with an SSC did not differ from patients without SSCs in terms of perioperative findings or operation related data (Table II). Length of stay was similar in both groups. Women who had a longer wound treatment with suction drains due to higher production of wound fluid were more likely to develop an SSC (Table II). Women who underwent a complete lymphadenectomy were more likely to develop an SSC $(\mathrm{n}=10 ; 50 \%)$ compared to those who were operated using the sentinel technique $(\mathrm{n}=1,5 \%, p=0.012)$.

\section{Discussion}

In the presented series eleven out of 20 patients (55\%) who received bilateral NWPT in the groin following lymphadenectomy or sentinel extirpation for early stage 
Table II. Comparison of mean values and medians for perioperative and operation related data between patients with and without surgical site complications.

\begin{tabular}{|c|c|c|c|c|c|}
\hline & $\begin{array}{l}\text { Pat. with SSC } \\
n=10\end{array}$ & IQR or $95 \% \mathrm{CI}$ & $\begin{array}{l}\text { Pat. without SSC } \\
n=10\end{array}$ & IQR or $95 \%$ CI & $p$-Value \\
\hline Operation time (min) & 139.5 & $(\mathrm{IQR}=105.0-174.8)$ & 126.0 & $(\mathrm{IQR}=78.2-176.2)$ & 0.97 \\
\hline Blood loss (ml) & 165.0 & $(\mathrm{IQR}=107.5-425.0)$ & 105.5 & $(\mathrm{IQR}=50.0-150.0)$ & 0.22 \\
\hline Duration of drainage right groin (days) & 11.0 & $(\mathrm{IQR}=11.0-22.3)$ & 3.0 & $(\mathrm{IQR}=3.0-6.5)$ & 0.05 \\
\hline Duration of drainage left groin (days) & 17.5 & $(\mathrm{IQR}=5.0-27.3)$ & 5.0 & $(\mathrm{IQR}=3.0-7.0)$ & 0.101 \\
\hline Number of LN removed right groin & 5.5 & $(95 \% \mathrm{CI}=3.2-7.8)$ & 4.6 & $(95 \% \mathrm{CI}=2.8-6.4)$ & 0.49 \\
\hline Number of LN removed left groin & 5.7 & $(95 \% \mathrm{CI}=3.6-7.5)$ & 4.6 & $(95 \% \mathrm{CI}=2.6-6.5)$ & 0.35 \\
\hline CRP perioperative (maximal) & 88.6 & $(95 \% \mathrm{CI}=25.5-151.7)$ & 81.1 & $(95 \% \mathrm{CI}=8.3-153.8)$ & 0.86 \\
\hline WCBC perioperative & 9.9 & $(95 \% \mathrm{CI}=8.2-11.6)$ & 9.9 & $(95 \% \mathrm{CI}=7.5-12.4)$ & 0.95 \\
\hline Duration of hospital stay (days) & 8.5 & $(\mathrm{IQR}=7.2-12.0)$ & 8.0 & $(\mathrm{IQR}=7.0-9.0)$ & 0.85 \\
\hline Duration of PICO treatment (days) & 16.4 & $(95 \% \mathrm{CI}=12.9-19.8)$ & 15.0 & $(95 \% \mathrm{CI}=11.3-18.7)$ & 0.32 \\
\hline
\end{tabular}

SSC: Surgical site complication; IQR: interquartile range; CI: confidence interval; LN: lymph node; CRP: C-reactive protein; WCBC: white cells blood count.

vulva cancer, developed at least one type of SSC within the first three months after the operation.

Even though the complication frequency of 55\% appears to be relatively high, it has to be noticed that nine out of those eleven women $(82 \%)$ had an SSC of mild character.

In all women with an isolated SSI $(n=3)$, the complication was classified as superficial, according to the CDC classification, and could be treated conservatively with administration of oral antibiotics. Also, when applying the ASEPSIS score, isolated SSIs were either classified as minor or moderate. The same observed length of hospital-stay in patients with and without SSCs supports the view that the SSCs were indeed predominantly minor.

Furthermore, one case of postoperative wound rupture became apparent several weeks after the completed PICO ${ }^{\mathrm{TM}}$ treatment in connection with an anticoagulation induced hemorrhage. Even though this patient did not show the picture of a typical primary healing complication, the case was classified as SSC, as clinical signs of a concomitant SSI were present.

The overall frequency of major $(n=2 ; 10 \%)$ or combined $(n=1 ; 5 \%)$ SSCs was relatively low when compared to the literature. Three retrospective studies evaluating the incidence of healing disorders in the groin after vulva cancer surgery report overall complication frequencies varying between 40-75\%, measured among patient cohorts of about 100-200 women. Severe healing complications, such as wound rupture, were reported in about $20-30 \%$ (9-12). Furthermore, we have reviewed our own experience, evaluating 121 women operated with lymphadenectomy between 2013 and 2015 for early stage vulva cancer. The overall wound complication rate was $45 \%$ and wound ruptures occurred in more than $40 \%$ of the investigated women (Maddalena Falagario, Department of Gynecology, Lund University Hospital).
During the actual follow-up period three patients were readmitted, however, surgical intervention was needed in one woman only. It seems that a combined wound management consisting of suction drain and NPWT using the PICO ${ }^{\mathrm{TM}}$ device reduces the severity of wound complications in the groin area after lymph node dissection. Even though most of the lymphatic fluid is still removed via the suction drains, the PICO $^{\text {TM }}$ dressing seems to help remove the remaining wound exudate via internal absorption and/or evaporation through its semipermeable layer.

The fact that the $\mathrm{PICO}^{\mathrm{TM}}$ dressing helps minimize the accumulation of fluid in the wound area is of clinical importance, as the development of early postoperative lymphocele formation is associated with a higher risk for long-term complications in the groin area (6). Both in vitro and in vivo experiments have demonstrated that the $\mathrm{PICO}^{\mathrm{TM}}$ dressing is able to handle clinically relevant production of wound fluid at both high and low exudate conditions (14).

Based on our clinical observations, we would recommend to not discontinue the $\mathrm{PICO}^{\mathrm{TM}}$ treatment during the first two weeks after the operation, as it seems that most SSCs following lymphadenectomy develop during the early postoperative period. This also accounts for women operated using the sentinel procedure. Furthermore, there is no evidence in the literature that the risk of developing a SSC increases proportionally with the amount of dissected lymph nodes (6).

As the $\mathrm{PICO}^{\mathrm{TM}}$ dressing complements the action of the suction drain, we assume that the NPWT treatment should be continued as long as the suction drains remain in place. The clinical significance of suction drains in the management of groin wounds following lymph node dissection is a controversy in the literature. While some studies report a protective effect of volume-controlled drainage (21), other authors state that drainage time has no influence on the onset of short- or long-term complications $(9,10)$. In our case, series 
drains were removed when the drainage volume was less than $50 \mathrm{ml}$ within $24 \mathrm{~h}$. Women with a higher drain production and therefore extended treatment with active suction drains were more likely to develop some kind of postoperative SSC. Despite this, due to the limited number of patients, we cannot conclude if these two parameters are predictors of the postoperative onset of healing disorders in the groin.

In our series, the application of NPWT could not totally prevent the development of SSCs or SSIs, as three patients developed a mild redness of the skin and in one case local infection signs were observed on the skin surrounding a wound rupture. In all four patients positive swab cultures were found, supporting the initiation and/or continuation of antibiotic therapy. However, the isolated type of bacteria was not the virulent Staphylococcus aureus in these four cases and the technique of swabbing was not standardized, which usually increases the risk of culturing contaminators $(22,23)$. In two patients of our series a wound culture was obtained despite the absence of clinical infection signs. Quantitative analysis showed a low concentration of anaerobial bacteria in one and of Staphylococcus aureus in the other patient. In both cases the bacterial burden was lying below the threshold value indicative for a significant clinical infection. Even though the two women received antibiotic treatment we decided not to classify their wound healing complication as an SSI, as neither clinical signs nor microbiological evidence were present.

As we only observed SSIs of superficial character it can be argued that the minimization of the interstitial wound fluid provided by the semipermeable $\mathrm{PICO}^{\mathrm{TM}}$ dressing may help to reduce the bioburden in the wound area. Furthermore, in the literature it has been shown that NPWT can be used in a variety of closed high-risk surgical incisions $(17,18,25$, $26,27)$ and is associated with an improved clinical outcome when compared to standard wound dressings $(24,25)$.

Furthermore, the results of a meta-analysis including 16 studies have shown that the postoperative application of negative pressure was associated with a significant reduction of SSIs (28). Nevertheless, these results are based on the evaluation of surgical, orthopedic and obstetric wounds, while there are no data in the literature regarding the impact of NPWT after groin lymphadenectomy in vulva cancer or other oncological patients.

Our findings suggest that NPWT is a promising strategy to minimize the severity of SSCs and especially SSIs in the groin area following radical lymphadenectomy or sentinel procedure in vulva cancer patients. However, as the presented study is limited by its low number of patients, more clinical investigations with larger patient cohorts and longer followup intervals are needed to confirm our assumption. Another critical issue is the fact that there is no validated classification system for wound healing disorders caused by vulva cancer or other types of gynecological cancer surgery.
In our series, the assessment of an SSI was based on clinical findings as well as the presence of a pathogenic microorganism on wound swab culture. A drawback of the objective CDC and ASEPSIS classification systems is the less critical evaluation of wound swab cultures in relation to clinical findings, and the risk of interpreting microbiological findings indicative of bacterial contamination as SSI. This misclassification can lead to a higher proportion of false positive SSIs resulting in unnecessary antibiotic treatment.

According to our data, it seems that NPWT administered using the $\mathrm{PICO}^{\mathrm{TM}}$ device can reduce the severity of SSCs in the groin after lymphadenectomy in vulva cancer patients. We assume that the $\mathrm{PICO}^{\mathrm{TM}}$ dressing complements the action of the suction drain, and suggest that the NPWT treatment should be continued as long as the suction drains remain in place.

As most of the complications appear within the early postoperative period, the $\mathrm{PICO}^{\mathrm{TM}}$ treatment should be considered for at least 14 days postoperatively. A larger randomized trial is warranted.

\section{Conflicts of Interest}

All Authors declare no conflicts of interest.

\section{Authors' Contributions}

KCA: Study design, acquisition and interpretation of data, manuscript drafting. SA: Study design and revision of the manuscript. CB: Study design and manuscript revision.

\section{References}

1 Meltzer-Gunnes CJ, Smastuen MC, Kristensen GB, Trope CG, Lie AK and Vistad I: Vulvar carcinoma in Norway: A 50-year perspective on trends in incidence, treatment and survival. Gynecol Oncol 145(3): 543-548, 2017. PMID: 28356187. DOI: 10.1016/j.ygyno.2017.03.008

2 Schuurman MS, van den Einden LC, Massuger LF, Kiemeney LA, van der Aa MA and de Hullu JA: Trends in incidence and survival of Dutch women with vulvar squamous cell carcinoma. Eur J Cancer 49(18): 3872-3880, 2013. PMID: 24011936. DOI: $10.1016 /$ j.ejca.2013.08.003

3 Hacker NF and Barlow EL: Staging for vulvar cancer. Best Pract Res Clin Obstet Gynaecol 29(6): 802-811, 2015. PMID: 25842047. DOI: 10.1016/j.bpobgyn.2015.01.004

4 Van der Zee AG, Oonk MH, De Hullu JA, Ansink AC, Vergote I, Verheijen RH, Maggioni A, Gaarenstroom KN, Baldwin PJ, Van Dorst E, Van der Velden J, Hermans RH, van der Putten H, Drouin P, Schneider A and Sluiter WJ Sentinel node dissection is safe in the treatment of early-stage vulvar cancer. J Clin Oncol 26(6): 884-889, 2008. PMID: 18281661. DOI: 10.1200/ JCO.2007.14.0566

5 Te Grootenhuis NC, van der Zee AG, van Doorn HC, van der Velden J, Vergote I, Zanagnolo V, Baldwin PJ , Gaarenstroom KN, van Dorst EB, Trum J, Slangen BFM, Runnebaum IB, Tamussino K, Hermans RH, Provencher DM, de Bock GH, de Hullu JA and Oonk MHM: Sentinel nodes in vulvar cancer: Long-term follow- 
up of the groningen international study on sentinel nodes in vulvar cancer (groinss-v) i. Gynecol Oncol 140(1): 8-14, 2016. PMID: 26428940. DOI: 10.1016/j.ygyno.2015.09.077

6 Hinten F, van den Einden LC, Hendriks JC, van der Zee AG, Bulten J, Massuger LF van de Nieuwenhof HP and de Hullu JA: Risk factors for short- and long-term complications after groin surgery in vulvar cancer. Br J Cancer 105(9): 1279-1287, 2011. PMID: 21970884. DOI: 10.1038/bjc.2011.407

7 Fonseca-Moutinho JA, Coelho MC and Silva DP: Vulvar squamous cell carcinoma. Prognostic factors for local recurrence after primary en bloc radical vulvectomy and bilateral groin dissection. J Reprod Med 45(8): 672-678, 2000. PMID: 10986688.

8 Pouwer AW, Arts HJ, van der Velden J and de Hullu JA: Limiting the morbidity of inguinofemoral lymphadenectomy in vulvar cancer patients; a review. Expert Rev Anticancer Ther 17(7): 615-624, 2017. PMID: 28608762. DOI: 10.1080/ 14737140.2017 .1337513

9 Gaarenstroom KN, Kenter GG, Trimbos JB, Agous I, Amant F, Peters AA and Vergote I: Postoperative complications after vulvectomy and inguinofemoral lymphadenectomy using separate groin incisions. Int J Gynecol Cancer 13(4): 522-527, 2003. PMID: 12911732 . DOI: 10.1046/j.1525-1438.2003.13304.x

10 Gould N, Kamelle S, Tillmanns T, Scribner D, Gold M, Walker J, Mannel R: Predictors of complications after inguinal lymphadenectomy. Gynecol Oncol 82(2): 329-332, 2001. PMID: 11531288. DOI: 10.1006/gyno.2001.6266

11 Pontre J, Harding J, Chivers P, Loughlin L, Leung Y, Salfinger SG, Tan J, Mohan GR and Cohen PA: Do groin drains reduce postoperative morbidity in women undergoing inguinofemoral lymphadenectomy for vulvar cancer? Int J Gynecol Cancer 28(1): 183-187, 2018. PMID: 29252926. DOI: 10.1097/ IGC.0000000000001146

12 Cirik DA, Karalok A, Ureyen I, Tasci T, Kalyoncu R, Turkmen $\mathrm{O}$, Kose MF, Tulunay $\mathrm{G}$ and Turan $\mathrm{T}$ : Early and late complications after inguinofemoral lymphadenectomy for vulvar cancer. Asian Pac J Cancer Prev 16(13): 5175-5179, 2015. PMID: 26225649. DOI: 10.7314/apjcp.2015.16.13.5175

13 Farrell R, Gebski V and Hacker NF: Quality of life after complete lymphadenectomy for vulvar cancer: Do women prefer sentinel lymph node biopsy? Int J Gynecol Cancer 24(4): 813-819, 2014. PMID: 24662129. DOI: 10.1097/IGC.0000000000000101

14 Malmsjo M, Huddleston E and Martin R: Biological effects of a disposable, canisterless negative pressure wound therapy system. Eplasty 14: e15, 2014. PMID: 24741386.

15 Atkins BZ, Wooten MK, Kistler J, Hurley K, Hughes GC and Wolfe WG: Does negative pressure wound therapy have a role in preventing poststernotomy wound complications? Surg Innov 16(2): 140-146, 2009. PMID: 19460818. DOI: 10.1177/ 1553350609334821

16 Kilpadi DV and Cunningham MR: Evaluation of closed incision management with negative pressure wound therapy (cim): Hematoma/seroma and involvement of the lymphatic system. Wound Repair Regen 19(5): 588-596, 2011. PMID: 22092797. DOI: $10.1111 / \mathrm{j} .1524-475 X .2011 .00714 . \mathrm{x}$

17 Karlakki S, Brem M, Giannini S, Khanduja V, Stannard J and Martin R: Negative pressure wound therapy for managementof the surgical incision in orthopaedic surgery: A review of evidence and mechanisms for an emerging indication. Bone Joint Res 2(12): 276-284, 2013. PMID: 24352756. DOI: 10.1302/ 2046-3758.212.2000190
18 Nordmeyer M, Pauser J, Biber R, Jantsch J, Lehrl S, Kopschina C, Rapke C, Bail HJ, Forst R and Brem MH: Negative pressure wound therapy for seroma prevention and surgical incision treatment in spinal fracture care. Int Wound J 13(6): 1176-1179, 2016. PMID: 25932993. DOI: 10.1111/iwj.12436

19 Mangram AJ, Horan TC, Pearson ML, Silver LC and Jarvis WR: Guideline for prevention of surgical site infection, 1999. Hospital infection control practices advisory committee. Infect Control Hosp Epidemiol 20(4): 250-278; quiz 279-280, 1999. PMID: 10219875 . DOI: $10.1086 / 501620$

20 Wilson AP, Treasure T, Sturridge MF and Gruneberg RN: A scoring method (asepsis) for postoperative wound infections for use in clinical trials of antibiotic prophylaxis. Lancet 1(8476): 311-313, 1986. PMID: 2868173. DOI: 10.1016/s0140-6736(86)90838-x

21 Pouwer AW, Hinten F, van der Velden J, Smolders RGV, Slangen BFM, Zijlmans HJMAA IntHout J, van der Zee AGJ, Boll D, Gaarenstroom KN, Arts HJ and de Hullu JA: Volume-controlled versus short drainage after inguinofemoral lymphadenectomy in vulvar cancer patients: A dutch nationwide prospective study. Gynecol Oncol 146(3): 580-587, 2017. PMID: 28687171. DOI: 10.1016/j.ygyno.2017.06.031

22 Gardner SE, Frantz RA, Saltzman CL, Hillis SL, Park H and Scherubel M: Diagnostic validity of three swab techniques for identifying chronic wound infection. Wound Repair Regen 14(5): 548-557, 2006. PMID: 17014666. DOI: 10.1111/j.17436109.2006.00162.x

23 Kallstrom G: Are quantitative bacterial wound cultures useful? J Clin Microbiol 52(8): 2753-2756, 2014. PMID: 24648547. DOI: $10.1128 / \mathrm{JCM} .00522-14$

24 Hyldig N, Birke-Sorensen H, Kruse M, Vinter C, Joergensen JS, Sorensen JA, Morgensen O, Lamont RF and Bille C: Metaanalysis of negative-pressure wound therapy for closed surgical incisions. Br J Surg 103(5): 477-486, 2016. PMID: 26994715. DOI: $10.1002 /$ bjs. 10084

25 Galiano RD, Hudson D, Shin J, van der Hulst R, Tanaydin V, Djohan R, Duteille F, Cockwill J, Megginson S and Huddleston E: Incisional negative pressure wound therapy for prevention of wound healing complications following reduction mammaplasty. Plast Reconstr Surg Glob Open 6(1): e1560, 2018. PMID: 29464150. DOI: $10.1097 /$ GOX.0000000000001560

26 Sandy-Hodgetts $\mathrm{K}$ and Watts R: Effectiveness of negative pressure wound therapy/closed incision management in the prevention of post-surgical wound complications: A systematic review and meta-analysis. JBI Database System Rev Implement Rep 13(1): 253-303, 2015. PMID: 26447018. DOI: 10.11124/ jbisrir-2015-1687

27 Virgilio E, Ceci D and Cavallini M: Surgical endoscopic vacuum-assisted closure therapy (EVAC) in treating anastomotic leakages after major resective surgery of esophageal and gastric cancer. Anticancer Res 38(10): 5581-5587, 2018. PMID: 30275175. DOI: 10.21873/anticanres.12892

28 Strugala V and Martin R: Meta-analysis of comparative trials evaluating a prophylactic single-use negative pressure wound therapy system for the prevention of surgical site complications. Surg Infect (Larchmt) 18(7): 810-819, 2017. PMID: 28885895. DOI: $10.1089 /$ sur.2017.156

Received August 9, 2020

Revised September 13, 2020 Accepted September 14, 2020 